\title{
Plate Tectonics as a Far- From- Equilibrium Self-Organized System
}

\author{
Don L. Anderson \\ Seismological Laboratory, California Institute of Technology, 1200 E. California Blvd., Pasadena, California
}

Contained fluids heated from below spontaneously organize into convection cells when sufficiently far from conductive equilibrium. Fluids can also be organized by surface tension and other forces at the top. Plate tectonics was once regarded as passive motion of plates on top of mantle convection cells but it now appears that continents and plate tectonics organize the flow in the mantle. The flow is driven by instability of the cold surface layer and near-surface lateral temperature gradients. Plate tectonics may be a self-driven far-from-equilibrium system that organizes itself by dissipation in and between the plates. In this case the mantle is a passive provider of energy and material. The effect of pressure suppresses the role of the lower thermal boundary layer. I suggest that the state of stress in the lithosphere defines the plates, plate boundaries and locations of midplate volcanism, and that fluctuations in stress are responsible for global plate reorganizations and evolution of volcanic chains. Stress controls the orientations and activity of volcanic chains. The state of stress in the lithosphere is probably more important than the temperature of the mantle in localizing volcanism, although the normal variations of temperature in the mantle influence the topography and stress of the plate. Stress also controls the strength of the lithosphere. Volcanic chains should be regarded as stress-gauges and not as indicators of absolute plate motions. Changes in the orientation and magmatic activity of volcanic chains (e. g. Hawaiian and Emperor chains) cannot be due to abrupt changes in plate motions but can reflect changes in stress.

\section{INTRODUCTION}

Plate tectonics on Earth, at present, consists of about a dozen large semi-rigid plates, of irregular shapes and sizes, separated by boundaries which meet at triple junctions. There are also many broad zones of deformation [Figure 1]. The seven major plates, including, in some cases, large areas of distributed deformation account for $94 \%$ of the surface area of the Earth. Gordon [2000] recognizes 20

Plate Boundary Zones

Geodynamics Series 30

Copyright 2002 by the American Geophysical Union

10/1029/030GD22 plates and an equal number of broad zones of deformation. Asia and North America are collages of accreted terranes and the large Pacific plate grew by annexing neighboring plates [Hardeback and Anderson, 1996].

The larger continent-bearing plates have large fractions of their areas occupied by diffuse deformation zones and do not qualify in their entirety as rigid plates. In fact, at least $15 \%$ of the Earth's surface violates the rules of rigid plates and localized boundaries [Gordon and Stein, 1992].

It is interesting that packing of similar sized polygons or circles on a sphere leaves about $15 \%$ void space [Anderson, 2001b]. In a close-packed or random assemblage of discs the number of contacting neighbors (the coordination 


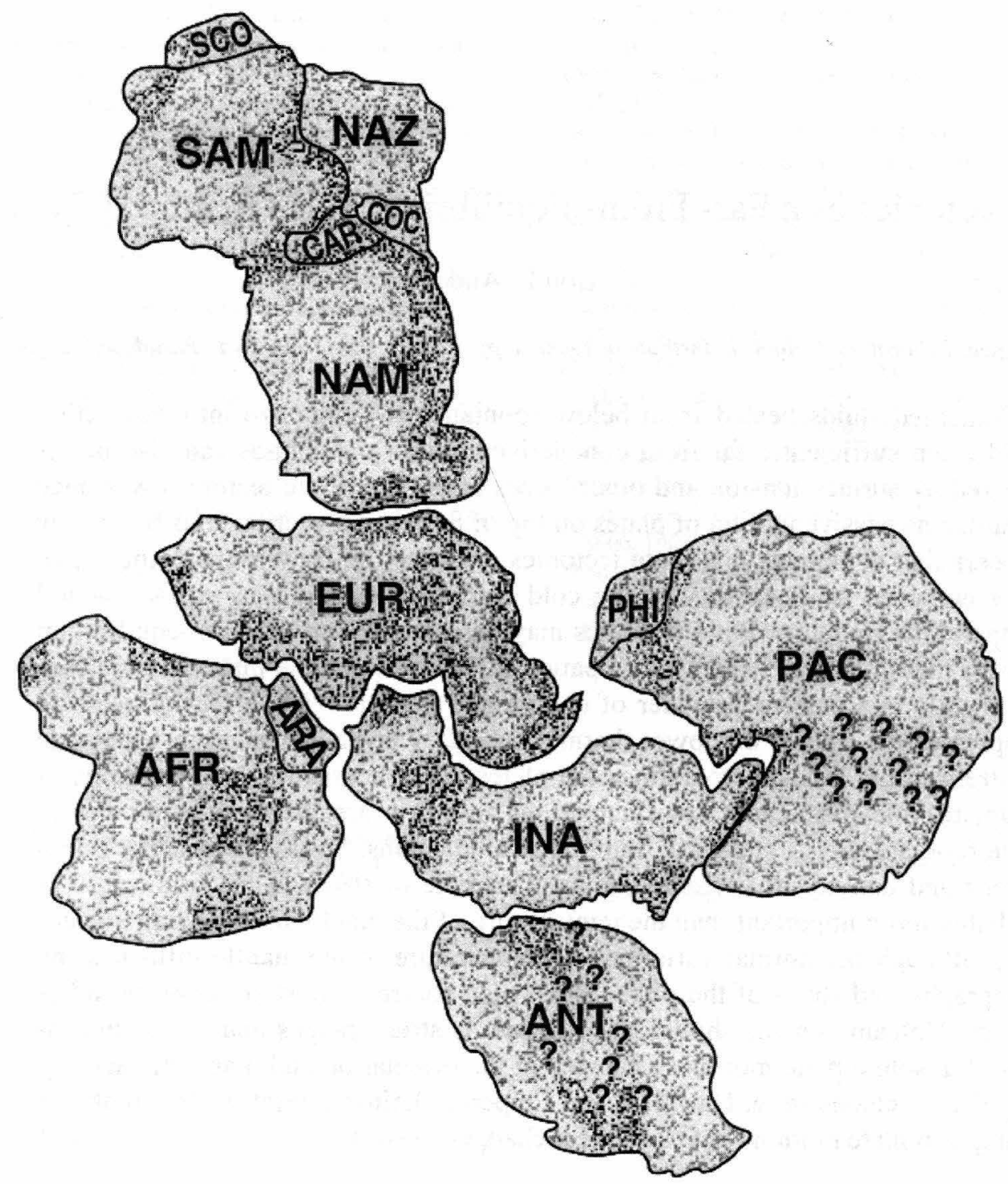

Figure 1. A disjointed Lambert equal-area projection centered on each plate. Note the band of medium sized plates encircling the large African and Pacific plates. Note the similarity in shape of AFR and PAC, and of EUR and INA. Regions of diffuse deformation are shown.

number) decreases as the size disparity of the discs increases. At some point the system loses rigidity, typically at 15\% void space [Trappe et al, 2001; Anderson, 2001b]. Six-coordinated structures tend to be rigid. Five-fold coordination is rare in rigid crystals but is common in fluids and glasses, on the surface of spheres, and at foam dislocations.

The coordination numbers of the present plates are as follows [Anderson, 2001b];

í. nearest neighbors (NN) $4.8 \pm 1.2$

i i. next-nearest neighbors (NNN) $5.3 \pm 0.6$

These numbers were derived by counting all NN and
NNN, with and without various of the minor plates, and then averaging. These statistics are similar to those found in coarsening 2D soap froths [Weaire and Hutzler, 1999]. $\mathrm{NN}$ is 6 for a static equilibrium foam. In a regular pentagonal dodecahedron each face has $5 \mathrm{NN}$ and $5 \mathrm{NNN}$ [Appendix, Note 1].

Ridges and trenches account about equally for $80 \%$ of the plate boundaries, the rest being transform faults. Most plates are not attached to a slab or bounded by a long transform fault. Most of the toroidal motion of the plate tectonic system is on the eastern side ( San Andreas fault) and SW 
side of the Pacific plate. There are short slab boundaries on many plates. There are some transforms on most ridge boundaries and some transform motion along many convergent zones. However, only a minor fraction of the total length of plate boundaries is slab and transform. Geometrically long slab boundaries have high convergence rates compared with spreading rates so less length is needed for a mass balance. Plates are not equal, in either size or configuration. These attributes of plates are not predicted, or even addressed, by current theories of plate tectonics and mantle convection.

A question arises; is the present situation typical, or more representative of a transitional state? Does active plate tectonics require a number of small "buffer plates" as well as the larger plates? Under what conditions, would the system jam or lock up? In a world of rigid non-subducting plates, the surface would lock-up at about $15 \%$ "porosity". Most plates are not attached to slabs and their freedom to move is constrained by the surrounding plates [Anderson, $2001 \mathrm{~b}]$.

Bubble rafts, or 2D foams, are classic minimum energy systems and show many similarities to plate tectonics. They are examples of soft matter. They readily deform and recrystallize (coarsen). Foams are equilibrium structures held together by surface tension. A variety of systems, including granular media and colloidal suspensions, exhibit nonequilibrium transitions from a fluid-like to a solid-like state characterized by jamming of the constituent particles [Trappe et al, 2001]. The jammed solid can be refluidized by temperature, vibration, or by an applied stress. These are termed fragile media [Cates et al, 1998]. Granular material and colloids tend to self-organize so as to be compatible with the load on them. They are held together by compression. They are rigid or elastic along compressional stress chains but they collapse and reorganize in response to other stresses, until they jam again in a pattern compatible with the new stresses. The system is weak to incompatible loads. Incompatible loads are those that differ from the stress system created the load bearing matrix. Changes in porosity, temperature or stress can trigger reorganization and changes in rigidity. The jamming of these materials prevents then from exploring phase space so their ability to self-organize is restricted.

In the plate tectonic context it is compression that keeps plates together. When the stress changes, plates may experience extension and collapse. New compatible plate boundaries must form. Widespread volcanism is to be expected in these un-jamming and reorganization events. These events are accompanied by changes in stress, and plate boundaries, rather than by abrupt changes in plate motions. Volcanic chains, which may be thought of as chains of tensile stress, can reorient, even if plate motions do not [Appendix, Note 2]. Jamming theory may be relevant to plate sizes, shapes and interactions [Cates et al., 1998; Anderson, 2001b]. The present plate mosaic is presumably consistent with the stress field that formed it but a different mosaic forms if the stresses change. Selforganization in granular material is discussed by Ottino and Khakhar, [2000].

Definitions. The definition of a plate boundary presupposes the definition of a plate and this in turn requires a definition of plate tectonics. Plate tectonics is usually supposed to be the surface manifestation of mantle convection. However, a fluid cooled from above or heated from within is driven by the unstable surface boundary layer and there are no active convective upwellings. The dense surface layer is the only active element and dense downwellings displace the interior fluid, forming passive upwellings [Appendix, Note 4]. The hexagonal planform of Bénard's experiments of 1900 was a result of surface tension at the top of the system, not the result of deep thermal instabilities as supposed by Lord Rayleigh and generations of Earth scientists. Likewise, plate tectonics and plates may be the result of forces at the surface, and the planform of mantle convection may be dictated by plate architecture and thermal and pressure perturbations in the mantle caused by plate tectonics [Richter, 1973; Bercovici, 1998; Anderson, 2001ab]. The mantle, of course, is the source of energy and material.

Plate tectonics is often viewed as the result of mantle convection or, simply, as the surface manifestaion of mantle convection. Part of the plate system is a full participant in mantle convection, acting as the surface conductive thermal boundary layer, and returning to the interior. Continents, oceanic crust and the depleted harzburgite layer, however, are intrinsically buoyant and do not readily sink just because they are cold. Likewise, these regions have high viscosity and resist falling off when they become unstable. The thickness of the outer shell is not a simple function of age, as is the case for simple boundary layer convection. Finally, lithospheric architecture, cooling and motion generate mantle convection currents. So, it is misleading to say that continental drift and plate tectonics are the result of mantle convection, or that the plates are simply the surface manifestation of mantle convection. Mantle convection would be completely different if there were no continents and if the surface had the same composition and rheology as the interior. One might instead consider that mantle convection is an important result of plate tectonics. This must be the case since most of the gravitational driving force is in the plate-slab system, and the mantle passively responds. The mantle can be 
regarded as the source of energy and material and a depository for some of the increase in entropy. The core is a secondary, almost trivial, source of energy.

Plates are often viewed as rigid; that is, strong. Alternatively, plates may be composed of entities which experience similar forces and move coherently, much as shoals of fish, flocks of geese, packets of commuters, and clouds. There is no rule that plate boundaries must be sharp. In fact, convection simulations have difficulty in explaining, in non ad hoc fashion, the existence of such boundaries. There is the strong possibility that plate tectonics requires continents and deformational or accommodation zones, as well as subduction zones . Coherent microplates (an illdefined term for plates smaller that Juan de Fuca, Rivera, etc) are common features of evolving plate boundaries, especially near triple junctions. The EPR evolved this way, as shown by the present Easter microplate [Engeln and Stein, 1984; Engeln et al., 1988; Naar and Hey, 1989], which results from the finite time required to transfer spreading from a growing to a dying ridge segment. A similar transfer of spreading generated the Juan Fernandez microplate at the Pacific-Nazca-Antarctic triple junction, such that a succession of microplates cause the triple junction to evolve northward [Anderson-Fontana et al., 1986]. This also seems to be true for continental plate boundaries such as the Afar block at the Nubia-Somalia-Arabia triple junction [Acton et al., 1991] and a paper in this volume [Stein et al., 2001] proposes such a model for the India-ArabiaEurasia junction. Iceland may be an unstable and evolving microplate [Foulger, 2002].

Rocks are strong in compression and weak in tension. They are particularly weak in tension if they are overlain by oceans and underlain by pockets of buoyant magma. Fluids can break rocks that experience tensile stresses. Rocks are also weak in tension when they occur as large masses.The forces on the lithosphere include thermal and gravitational forces. Gravitational forces are responsible for the wellknown but ill-named ridge push and slab pull forces. They are not boundary or local forces but are distributed over the whole plate Plate tectonics introduces density anomalies into the mantle which cause convection and further forces on the plates. The integral of these forces partly determines the motion of the surface plates. These motions are resisted by forces in and between the plates, and by viscosity of the mantle. Together, the driving and resisting forces control the motion and stress in the surface layer. It is the present thesis that these stresses also define the plates and the plate boundaries. Regions of lateral compression behave as coherent plates while regions of lateral effective extension are candidates for plate boundaries and volcanic chains [Figure 2]. Thus, the motions of plates are controlled by the inte- gral of gravitational and resisting forces, and plate boundaries are defined by the sign of local force fields. Driving forces can change only gradually while some resisting forces, such as continental collisions, can change rapidly. This is because the driving forces are body forces and act on the whole plate. Resisting forces are localized. Examples of changes in resisting forces are the India-Asia collision, and the final separation of South America and Africa along a transform fault. Both events appear in the global tectonic and magmatic record. Likewise, one can note the relation between Nasca plate speeds and Andean uplift [Norabuena et al, 1999]. Quite often these global and regional correlations are attributed to massive mantle overturns, mantle avalanches or superplumes, the implication being that convection in the mantle controls plate tectonics and episodicities. If the mantle is passive, global plate reorganizations must be caused by the plates themselves.

When the stress system changes in the plate mosaic the plates and plate boundaries can redefine themselves. Thus, the plate mosaic itself is a result of the global stress field, forces on the lithosphere, and history. In this respect an aggregation of plates differs from a granular material in which each grain is invariant. This perception of plate tectonics is more akin to recrystallation, deformation of foam, and other far-from-equilibrium self-organized structures. Volcanoes are stress-gauges, not motion detectors [Appendix, Note 4].

The word plume is seldom defined in the geodynamics literature and it is used with a variety of meanings. Technically, a plume can be either hot or cold and it rises or falls through a surrounding fluid because of its positive or negative buoyancy. In the geodynamics context it usually refers to hot, narrow, buoyant upwellings from a deep unstable thermal boundary layer. In practice, the term is applied to any region which is perceived to be hotter than average or which has anomalous magmatism. Implicit in this usage is the assumption that the mantle otherwise would be isothermal at any given depth [Anderson, 2000; Korenaga, $2000]$. In geochemistry the primary attribute of a plume is a chemical signature that deviates from the average composition of Midocean Ridge Basalts (MORB). Again, the assumption is that otherwise the mantle would be chemically uniform. There are a variety of mechanisms for focusing magmatism, creating upwellings and driving convection so the word plume usually refers to those which involve a hot unstable lower thermal boundary layer [Appendix, Note 3]. It may be difficult to distinguish plume-caused features, if they exist, from small-scale convection, edge-driven gyres and eddies [ EDGE ], Richter rolls and sprouts [Richter, 1973], and the intrinsic three-dimensionality of upper mantle convection, whether active or passive. 


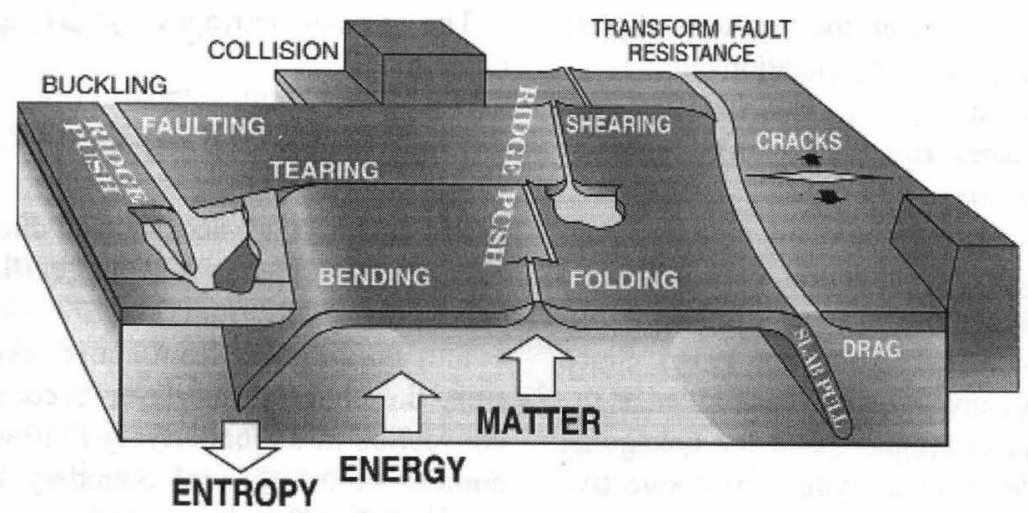

\begin{abstract}
Figure 2. Density and thermal inhomogeneities in the Earth exert force on the surface, resulting in regions of compression and regions of extension. The lithosphere can transmit lateral compressive forces but will fail in tension (the cathedral effect). Buoyant fluids in and below the lithosphere (water, magma) serve to lower the yield stress in rocks (hydrofracture), accentuating the tensile weakness. Thus, stress inhomogeneities, accentuate or create strength inhomogeneities creating conditions appropriate for the formation of cracks, dikes, volcanic chains and plate boundaries. Lateral compression is indicated by dark regions, extension by light areas, and potential plate boundaries by heavy lines. Plate boundaries are characterized by shallow extensional and strike-slip earthquakes, even in convergence zones.
\end{abstract}

End-Member Mechanisms. Some of the elements of plate tectonics are continental breakup, triple junctions, volcanic chains and large igneous provinces. There are two endmember hypotheses for explaining these elements, which are sometimes treated as independent from, or external to, the theory of plate tectonics. In one hypothesis - which can be called internal control - these phenomena are due to active upwelling thermal plumes. Plumes are used to break up continents and provide hot material to the upper mantle. They are predicted to be rare in subduction zones since the slab suppresses the development of the lower thermal boundary layer. Geochemistry papers, however, routinely invoke plumes in such places to provide helium isotopes in backarc basins. Since plumes are point sources of thermal and chemical pollution they need to be supplemented with the idea that plume material, once in the upper mantle, can flow for thousands of kilometers to service distant volcanic provinces. The usual plume hypothesis depends on viscosity being a strong function of temperature and hence acting as a conduit. The lateral flow of plume material below the lithosphere, and along ridges, is not an intrinsic part of the plume hypothesis. Temperature dependence of viscosity also affects plate driven convection and upper mantle convection can also be channeled by the asthenosphere. Large lateral flow is not required if the mantle is at the melting point and if the so-called plume components of magma are in a shallow enriched layer or dispersed throughout the upper mantle.

In the other extreme end-member hypothesis plates break themselves and triple-junctions are a natural result of gen- eral minimization or geometric principles that yield triplejunctions in such diverse systems as mudcracks, basalt columns, bubble rafts and honeycombs. Plate tectonics introduces density, chemical and thermal anomalies into an already hot mantle [Anderson, 2000] and large volumes of basalts are a natural result of triple-junction and new plateboundary formation. The absence of magmatism implies the presence of lateral compression in the lithosphere; i. e. magmatism is controlled by the lithosphere, not by deep convective upwellings. Various scales of convection, however, are driven by plate tectonics [Richter, 1973; Anderson, 1998]. The numerous papers and conferences on plume-ridge and plume-transform fault interactions attests to the general perceived independence of plate features and volcanism. Many hotspots are on transforms and ridges and a single explanation involving small scale convection, focussing, three-dimensionality and edge effects seems preferable to invoking an independent deep thermal boundary layer. Deep mantle plumes are suppressed by the effects of pressure on viscosity, thermal conductivity and thermal expansion [Anderson, 2001a], and, possibly, by chemical stratification. The Rayleigh number of the lower mantle is very low. If the mantle is almost entirely heated from within, and cooled from above, there is no lower thermal boundary layer. All upwellings are passive.

Rayleigh-Like Numbers. The first order questions of mantle dynamics include;

1. Why does Earth have plate tectonics?

2. What controls the onset of plate tectonics, the 
number, shape and sizes of the plates, the locations of plate boundaries and the onset of plate reorganization?

3. What is the organizing principle for plate tectonics; is it driven or organized from the top or by the mantle? What, if anything, is minimized?

In 1900 Henri Bénard heated whale oil in a pan and noted a system of hexagonal convection cells [Bénard, 1900]. Lord Rayleigh analyzed this in terms of the instability of a fluid heated from below [Rayleigh, 1916]. Since that time Rayleigh-Bénard convection has been taken as the classic example of thermal convection, and the hexagonal planform has been considered to be typical of convective patterns at the onset of thermal convection. It was not until 1958 that Pearson [1958] showed that Bénard's patterns were actually driven from above, by surface tension, not from below by an unstable thermal boundary layer. Later experiments showed the same style of convection when the fluid was heated from above, cooled from below or when performed in the absence of gravity [Scriven and Sternling, 1960; Velarde and Normand, 1980]. This confirmed the top-down surface driven nature of the convection which is now called Marangoni or Bénard-Marangoni convection [Velarde and Normand, 1980]. It operates even when there is no thermal buoyancy. It is controlled by a dimensionless number, $\mathrm{ma}$;

$$
m a=\sigma \Delta \mathrm{TD} / \rho \mathrm{uK}
$$

where $\sigma$ is the temperature derivative of the surface tension, $\mathrm{S}, \Delta \mathrm{T}$ is the temperature difference, $\mathrm{D}$ is the layer depth, and $\rho, U$ and $K$ are the density, kinematic viscosity and thermal diffusivity of the layer [Scriven and Sternling, 1960; Velarde and Normand, 1980]. When the Marangoni number is much larger than the Rayleigh number, surface tension forces dominate over gravitational buoyancy forces and the system is driven, and organized, from above (even if the source of heating is from below ). Both sets of forces can be important, depending on the parameters and the depth of the fluid. Even Rayleigh convection can be controlled from the top if there is surface cooling but an isothermal bottom. In this case there is no lower thermal boundary layer.

In Benard-Marangoni convection fluid is drawn up at warm regions of the surface and flows toward cell boundaries where it returns to the interior [Appendix, Note 5]. It is the horizontal gradient in surface tension that drives the surface layer. In the plate tectonic situation the horizontal gradient in gravitational forces is responsible for surface motions. Cell sizes in both Marangoni and Rayleigh convection are of the order of the fluid depth at the onset of convection.
The thermal buoyancy, g $\alpha \Delta T$, appears in the Rayleigh number;

$$
\mathcal{R a}=\mathbf{g} \alpha \Delta \mathrm{T} \mathrm{D}^{3} / \mathrm{uk}
$$

where $g$ and $\alpha$ are acceleration due to gravity and thermal expansivity. Systems with large $M a$ or $\mathcal{R a}$ are far from conductive equilibrium.

In a fluid cooled from above, even without surface tension, the cold surface layer becomes unstable and drives convection in the underlying fluid when the local Rayleigh number of the thermal boundary layer (TBL) exceeds a critical value, $\mathcal{R} a_{\mathrm{cr}}$,

$$
\mathcal{R} a_{\mathrm{cr}}=\mathrm{g} \alpha_{\ell} \Theta \delta^{3} / \mathrm{v}_{\ell} \mathrm{K} \ell_{\ell}
$$

where $\Theta$ is the temperature increase across the thermal boundary layer of thickness $\delta$ and the subscripts refer to properties of the boundary layer. Like Marangoni convection, this type of convection is driven from the top. Cold downwelling plumes are the only active elements; the upwellings are passive, reflecting mass balance rather than thermal instabilities [Zhong and Gurnis, 1995; Turcotte and Schubert, 1982].

Plate tectonics, to a large extent, is driven by the unstable surface thermal boundary layer and therefore resembles convection in fluids which are cooled from above. A similar analysis can be done for the lower TBL of a fluid heated from below. Pressure decreases $\alpha$ and increases $U$ and $k$ so it is hard to generate buoyancy or vigorous small-scale convection (high $\mathcal{R} a$ ) at the base of the mantle [Anderson, 1989; Tackley, 1998a]. In addition, heat flow across the $\mathrm{CMB}$ is about an order of magnitude less than at the surface so it takes a long time to build up buoyancy. In contrast to the upper TBL (frequent ejections of narrow dense plumes), the lower TBL is sluggish and does not play an active role in upper mantle convection [Anderson, 2001a]. Core-mantle boundary (CMB) upwellings are thousands of kilometers in extent [Tackley, 1998a; Ritsema and van Heijst, 2000; Dziewonski, 2000] and embedded in highviscosity mantle [Appendix, Note 6].

There are additional surface effects. Lithospheric architecture and slabs set up lateral temperature gradients that drive small-scale convection [Richter, 1973; Anderson, 1998b; King and Anderson, 1998; King and Ritsema, 2000]. For example, a newly opening ocean basin juxtaposes cold cratonic temperatures of about $1000^{\circ} \mathrm{C}$ at $100 \mathrm{~km}$ depth with asthenospheric temperatures of about $1400^{\circ} \mathrm{C}$. This lateral temperature difference, $\Theta$, sets up convection, the vigor of which is characterized by the Elder number, 


$$
\varepsilon \ell=g \alpha \Theta \mathrm{L}^{3} / \mathrm{Ku}
$$

where $L$ is a characteristic horizontal dimension, e.g. the width of a rift or an ocean basin and $U$ is now the viscosity of the asthenosphere. Convective flows driven by this mechanism are episodic and can reach $15 \mathrm{~cm} / \mathrm{yr}[\mathrm{Ko}$ renaga, 2000] and may explain volcanism at the margins of continents and cratons, at oceanic and continental rifts, and along fracture zones and transform faults [Anderson et al., 1992; Anderson, 1998; Favela and Anderson, 2000]. Shallow upwellings by this mechanism are intrinsically $3 \mathrm{D}$ or plume-like [Korenaga, 2000] and can create such features as Iceland and Bermuda [Anderson, 1998]. Richter [1973] calls these vertical shallow-rooted cylindrical structures sprouts [Appendix, Note 3].

If the mantle is near the melting point then it is the absence of volcanoes in most parts of the world and the existence of non-volcanic margins that must be explained. This is the reverse of the main focus of current research which assumes a subsolidus mantle, and the necessity for core heat to provide melts to midplate volcanoes. The normal variations of temperature in a convecting mantle are about plus or minus 200 degrees centigrade [Anderson, 2000]. The deepest and slowest spreading ridges are magmatically productive. This implies that even the coldest parts of the mantle are not below the melting point. However, a range of 400 degrees ( from slab cooled mantle to mantle insulated by continents or large plates ) has a large effect on the amount of melt available. The rate of small scale convection at the edges of continents and cratons depends on the thickness and temperature of the colder or thicker plate and the history of this part of the mantle. One expects, in a convecting mantle, or on a planet dominated by plate tectonics, variations in chemistry and temperature of the upper mantle and in melt productivity.

Ridge migration is an essential feature of plate tectonics [Stein et al., 1977] and ridges are not therefore always over cold or average temperature mantle .Variations of melt productivity are expected along the global ridge system, even in the absence of 3D instabilities ( sprouts) and magma focusing, which must also occur. In a simple boundary layer theory of convection, without continents and ridge migration, the thinnest "plate" (thermal boundary layer ) is always over a hot upwelling.

Self-organization. A closed or isolated system at equilibrium returns to equilibrium if perturbed. A far-fromequilibrium dissipative system, provided with a steady source of energy or matter from the outside world, can organize itself via its own dissipation. It is sensitive to small internal fluctuations and prone to massive reorganization [Prigogine, 1980]. The fluid in a pot heated on a stove evolves rapidly through a series of transitions with complex pattern formation even if the heating is spatially uniform and slowly varying in time. The stove is the outside source of energy and the fluid provides the buoyancy and the dissipation (viscosity). Far-from-equilibrium self-organization and reorganization require; an open system, a large steady outside source of matter or energy, non-linear interconnectedness of system components, dissipation, and a mechanism for exporting entropy products [Prigogine, 1980]. Under these conditions the system responds as a whole, and in such a way as to minimize entropy production (dissipation). Certain fluctuations are amplified and stabilized by exchange of energy with the outside world. Structures appear which have different time and spatial scales than the energy input.

Plate tectonics is driven by negative buoyancy of the outer shell and is resisted by dissipation forces in the lithosphere (e.g. bending, deformation, faulting, sliding resistance) and in the mantle (viscosity); see Figure 3. If most of the buoyancy and dissipation is provided by the plates and the mantle simply provides heat, gravity, matter and an entropy dump then plate tectonics is a candidate for a selforganized system, in contrast to being organized by mantle convection or heat from the core (plumes). Plate tectonics is certainly a non-linear system and is far from stable mechanical or thermal equilibrium. Global plate reorganizations are recognized in the geological record [Rona and Richardson, 1978]. Multiple steady non-equilibrium states are possible [Monnereau and Quere, 2001; Sleep, 2000; Solomatov and Moresi, 1997; Tackley, 1998; van Keken and Ballentine, 1998].

Dissipative Structures. Patterns formed by instabilities in non-linear far-from-equilibrium open systems are called the dissipative structures of the system [Prigogine, 1980]. Transitions can be caused by mechanical, thermal or chemical fluctuations. Thermal instabilities in fluid dynamics result in the onset of convection and transitions from one state to another (e.g. rolls, cells, chaos). However, mechanical forces can also initiate instabilities (e.g. in beams, membranes and thin shells, dike intrusion and the break-up of sea ice). The onset of convection, in an unstable system that is far from conductive equilibrium, at a critical Rayleigh number is the classic example of a self-organized buoyancy driven fluid dynamic system [Prigogine, 1980] although we now know that the original Bénard patterns were organized by surface tension. Dissipative structures maintain themselves in a stationary state but they may evolve, slowly or rapidly [Appendix, Note 7]. Much of the literature on this subject is for static systems and static dissipation. What is needed is a theory of dynamic systems 

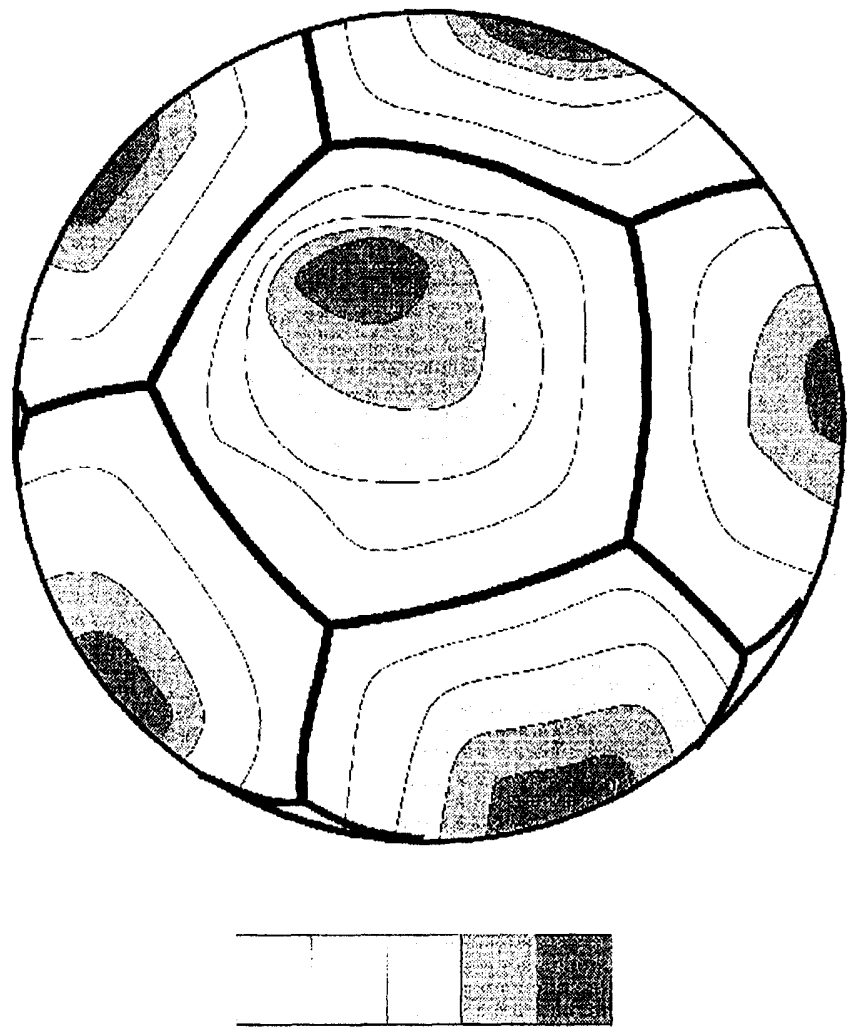

EXTENSION COMPRESSION

Figure 3. The driving and resisting (dissipative) forces in the lithosphere and asthenosphere. In a plate-free or lithosphere-free system the buoyancy and dissipative (viscosity) forces are in the fluid and it can self-organize (convection). In plate tectonics and Marangoni convection - the surface plays a different role and it can self-organize the fluid. The tectonic plates can be viewed as an open, far-from-equilibrium, dissipative and self-organizing system that takes matter and energy from the mantle and converts it to mechanical forces (ridge push, slab pull), which also drive the plates. Subducting slabs and cratonic roots cool the mantle and create pressure and temperature gradients, which drive mantle convection. The plate system thus acts as a template to organize mantle convection. In contrast, in the conventional view the lithosphere is simply the surface boundary layer of mantle convection and the mantle is the self-organizing dissipative system.

and dynamic dissipation. This subject is in its infancy. Background material on minimization in this kind of thermodynamics can be found in Bejan [1996].

Mantle Dynamics. The history of ideas regarding mantle convection parallels the development of ideas in fluid dynamics. Although the surface boundary layer and "slabpull" are now well understood and generally accepted as the prime-movers in plate tectonics there is a widespread perception that active hot upwellings from deep in the interior of the planet are responsible for "extraordinary" events such as plate reorganization, continental break-up, extensive magmatism and events far away from plate boundaries [Larson, 1991; Stein and Hofmann, 1994; Tackley et al., 1993; Davies, 1999]. Plate tectonics is considered to be an incomplete theory of mantle dynamics. Active upwellings from deep in the mantle [van Keken and Ballentine, 1998; Larson, 1991; Stein and Hofmann, 1994] are viewed as controlling some aspects of surface tectonics and volcanism, including reorganization, implying that the mantle is not passive. This is called the plume mode of mantle convection [Davies, 1999]. It relies on core heat.

However, numerical experiments show that mantle convection is controlled from the top by continents, cooling lithosphere and plate motions and that plates not only drive and break themselves but can control and reverse convection in the mantle [Gurnis, 1988; Gurnis and Zhong, 1991; Gurnis et al., 2000; Lowman and Jarvis, 1993]. Supercontinents and other large plates generate spatial and temporal temperature variations. The migration of continents, ridges and trenches cause a constantly changing surface boundary condition; the underlying mantle passively responds. Plates break up and move, and trenches roll back because of interactions of the surface with the slab created internal buoyancy of the mantle, not because of buoyancy that is independent of plate tectonics [Zhong and Gurnis, 1995; Gurnis and Zhong, 1991; Gurnis et al., 2000; Lowman and Jarvis, 1999]. Surface plates are constantly evolving and reorganizing although major reorganizations are infrequent. Plates are mainly under lateral compression although local regions having horizontal least-compressive axes may be the loci of dikes and volcanic chains [Favela and Anderson, 2000; Rubin, 1995; Bercovici, 1998; Miller and Nur, 2000]. Some of the phenomena that have been attributed to massive mantle overturns [Larson, 1991; Stein and Hofmann, 1994] are actually due to plate boundary reorganization [Hardeback and Anderson, 1996; Heller et al., 1996].

The fact that most active plate boundaries on Earth are under water may be crucial in attempting to understand plate tectonics on Earth, and its absence on other planets [Bercovici, 1998]. Water weakens rocks, lowers the melting point and lowers the viscosity of the mantle. A partially molten mantle lubricates the plate-mantle boundary; the buoyancy of magma (and water in the crust) fractures the lithosphere when it experiences even limited horizontal extension [Favela and Anderson, 2000; Rubin, 1995]. The thickening of oceanic plates as they cool generates gravitational forces which drives the plates and, in general, puts them into lateral compression, holding out the surrounding fluids, and keeping the plates together. The lithosphere is 
colder, drier and stronger than the underlying mantle. Rocks, however, are weak and permeable to fluids when under extension [Rubin, 1995; Bercovici, 1998; Miller and Nur, 2000]. These are possible sources of positive feedback and amplification of stress fluctuations.

The forces on plates can be decomposed into components which have been called ridge push, slab pull, trench suction, basal drag and so on [Forsyth and Uyeda, 1975]. The driving forces are thermal and gravitational in nature and change slowly. These are resisted by dissipative forces such as mantle viscosity, slab bending, transform fault friction and continental collision. Some of these latter forces can change rapidly, causing changes in internal stresses and the sizes and shapes of plates [Anderson, 2001b], and, possibly, the directions and velocities of plates. The motions of plates can respond only sluggishly to changes in stress.

Plates attached to long slabs tend to move rapidly. Plates which have large continental areas, including thick cratonic roots, tend to be more fixed with respect to each other and the mantle. However, there is no correlation in each group with the plate area or the amount of slab, continent or transform boundary [Forsyth and Uyeda, 1975]. This suggests that plate tectonics should be analyzed as a system rather than as a force balance on individual plates. The question then arises, are the plates, plate boundaries and motions a self-organizing system? And is it fluctuations in stress or temperature that trigger the reorganization?

Convection. For the last decade, three-dimensional spherical shell convection models have become progressively more sophisticated. However, in spite of progress in numerical accuracy and incorporation of pressure and temperature dependence of physical properties and of phase changes these models do not account for the first order tectonic features of the Earth, such as the number and sizes of plates [Monnereau and Quere, 2001; Sleep, 2000; Solomatov and Moresi, 1997; Tackley, 1998b; van Keken and Ballentine, 1998]. It has been possible to understand some of the features of plate tectonics by introducing mechanical heterogeneity and memory effects into the lithosphere [Zhong and Gurnis, 1995; Gurnis et al., 2000]. A remaining question, however, is what controls which weak zones are activated and what dictates their location and spacing and, hence, plate sizes and shapes. Active and inactive faults and old plate boundaries are numerous. They differ in strike, dip, orientation, age and age offset, mantle temperature, crustal thickness and strength. Such zones also concentrate stress so it may be stress rather than strength that dictates their availability for reactivation. Water pressure in the crust and lithosphere, and magma pressure below, may also control the locations of volcanic chains and new plate boundaries. The traditional way of trying to model plate motions is to start with a convecting mantle, driven by radioactive heating and heat from the core. Attempts are made to modify the rheology and failure criteria of the surface layer in order to initiate plate tectonic behavior [Monnereau and Quere, 2001; Sleep, 2000; Solomatov and Moresi, 1997; Tackley, 1998; van Keken and Ballentine, 1998; Gurnis, 1988; Gurnis and Zhong, 1991; Gurnis et al., 2000]. An important attribute of plate tectonics is the large amount of energy associated with toroidal (strike-slip) motions. This does not arise directly from buoyancy forces involved in normal convection. In a convecting system the buoyancy potential energy is balanced by viscous dissipation in the fluid. In plate tectonics, both buoyancy and dissipation are generated by the plates. The cooling plate and the slab provide the driving buoyancy and this may be balanced almost entirely by slab bending [Conrad and Hager, 1999] and by transform fault resistance as suggested by the toroidal/poloidal energy partitioning of plate motions [O'Connell et al., 1990] [Appendix, Note 8]. Even the cooling of the Earth is not completely governed by the viscosity of the mantle [Conrad and Hager, 1999; Christensen, 1985]. It is regulated by the plate tectonic system and, ultimately, by the distribution of stress in the lithosphere.

Plate Driven Flow. Marangoni convection is driven by surface tension [Pearson, 1958; Scriven and Sternling, 1960; Velarde and Normand, 1980]. Since surface tension is isotropic, the fluid flows radially from regions of low surface tension to the cell boundaries, which are hexagonal in planform, where linear downwellings form. The equivalent surface force in mantle convection is the ridge pushslab pull gravitational force which has the same units as surface tension. Since plates are not fluids the forces are not isotropic. Plates move from ridge to trench, pulling up material at diverging regions, which are the equivalent of the centers of Benard-Marangoni hexagons, and inserting cold material at subduction zones. The other difference between Marangoni and plate-driven convection is that plates are held together by lateral compression and fail in lateral extension. Cell boundaries are convergent and elevated and are regions of compressive stress in Marangoni convection.

The plate tectonic equivalent of the Marangoni number can be derived by replacing surface tension by plate forces. I define the plate tectonic or Platonic number

$$
\mathrm{P} \ell=\mathrm{g} \alpha \Delta \mathrm{TL}^{2} / \mathrm{u} \mathcal{D}(\mathrm{U})
$$

where $\mathrm{L}$ is a characteristic ridge-trench distance and $\mathrm{u}$ is plate velocity. $D(U)$ is a dissipation function which ac- 
counts for plate deformation, intraplate resistance and mantle viscosity. When the only resisting forces are lithospheric bending we have the dimensionless lithosphere number

$$
\mathrm{P} \ell=\rho g \alpha \Delta \operatorname{Tr}^{3} / \mathrm{KU}_{\ell}
$$

where $r$ is the radius of curvature of the bend and $v_{\ell}$ is the lithospheric viscosity [Conrad and Hager; 1999].

Currently, this is the only case where the dissipation function has been derived and quantified. When plate interactions are involved we also need coupling parameters across plates such as transform fault resistance and normal stress. In the plate-tectonic system the plates (and slabs) account for much of both the driving force and dissipation [Figure 3] and in this respect they play the role of the convecting fluid in Rayleigh-Benard convection (internal sources of both buoyancy and viscous dissipation). Both the buoyancy and dissipative stresses affect the whole system. The plate sizes, shapes and velocities are selfcontrolled and should be part of the solution rather than input parameters [Monnereau and Quere; 2001].

Multiple States. Far-from-equilibrium self-organized systems generally have multiple states available to them. They can stay in one state for a while ("stationary nonequilibrium") but fluctuations in the system (not necessarily imposed from outside) can cause dramatic reorganizations and the system ends up in a new state. There are stationary nonequilibrium states and transitional states, rather than steady-state or equilibrium states. Prigogine [1980] uses the Platonic expression "from being to becoming" to distinguish these situations. In the case of the Earth the tectonic styles available include stagnant lid, mobile lid, large vs. small plates, slow vs. fast plates, steady motions and catastrophes [Sleep, 2000; Solomatov and Moresi, 1997; Tackley, 1998a; van Keken and Ballentine, 1998; Tackley et al., 1993]. Each state can be characterized by a variety of individual plate configurations. For example, Earth today is in a metastable slowly varying configuration with some plates growing and some shrinking. About 200 million years ago, when Panagea broke up, new plates and plate boundaries formed, even in the Pacific hemisphere. The lithosphere is midway through a supercontinent cycle [Anderson, 1982; 1989]. In the slowly varyng state the stress patterns inside of plates are relatively invarient. Thus, volcanic chains and mountain belts stay more or less in the same places.

The Mid-Cretaceous was a period of plate boundary reorganization in the Pacific hemisphere, accompanied by growth of the Pacific plate by annexation of its neighbors (ridge and triple junction migration) and plateau formation at the bounding triple junctions [Heller et al., 1996; Hardebeck and Anderson, 1996]. The excess magmatism at this time is usually attributed to internal convective causes [Larson, 1991] but the rapid growth of the Pacific plate was erroneously attributed to rapid seafloor spreading rather than annexation [Hardebeck and Anderson, 1996].

Plate reorganizations have been attributed to temperature fluctuations in the convecting mantle [Larson, 1991; Stein and Hofmann, 1994; Tackley et al., 1993; Davies, 1999] but in geodynamic models dominated by plate interactions it is fluctuations in stress that reorganize the system. These include changing the sign of the lateral stress in the plate or the magnitude of the normal stresses across plate boundaries. These changes affect permeability [Miller and Nur, 2000] and can initiate or turn off fractures, dikes and volcanic chains [Favela and Anderson, 2000]. The mantle itself need play no active role whatsoever in plate tectonic "catastrophes" [Appendix, Note 9].

Surface Rheology. Recently, attention has focused on the rheology of the lithosphere in order to try to reproduce plate-like behavior [Solomatov and Moresi, 1997; Gurnis, 1988; Bercovici, 1998]. These attempts have provided insight into the importance of the outer shell in controlling mantle dynamics and thermal evolution but they do not address the first order questions of mantle dynamics and they have not yielded anything resembling plate tectonics. The most successful attempts are those that account for lithospheric heterogeneity and fault reactivation [Zhong and Gurnis, 1995; Gurnis et al., 2000]. Brittle-like failure of the lithosphere is involved in plate tectonics but modeling shows that plate velocity is nearly independent of the yield stress. This has been taken to mean that plate motion is resisted by viscous stresses in the mantle rather than by dissipation in the plate. However, bending stresses alone can be as important as mantle dissipation [Conrad and Hager, 1999]. The present system of plate motions serves to minimize the toroidal energy which implies a dominant role for the lithosphere in moderating plate driving forces [O'Connell et al., 1990]. The minimum dissipation hypothesis [Prigogine, 1980; O'Connell et al., 1990] is useful in global geodynamic calculations [Sleep et al., 1979]. The fact that plate velocity on Earth does not depend on plate size and that the velocities of the fast plates do not depend on length of the subduction boundary suggests that it is the system, not the individual plate, that dictates plate motions. The system appears to minimize toroidal energy, the individual plates do not [O'Connell et al., 1990]. 
Transform faults and the transform component of obligue subduction zones do no gravitational work to aid convection but they may dominate over other sources of dissipation (bending, collisional resistance, mantle viscosity), at least for the present configuration of plates [Appendix, Note 8]. It is conceivable that during the assembly of Panagea or the collision of Africa and India with Eurasia [Rona and Richardson, 1978] that collisional and bending resistance may have dominated until the subcontinents were sutured together and a global plate reorganization repartitioned the dissipation forces according to a minimum dissipation principle. The formation of plate boundaries may also be a self-organized process, although on a completely different scale [Miller and Nur, 2000].

Various schemes of mantle dynamics have been investigated that involve a dominant or active role for mantle convection, heat from the core, or interactions between individual plates and mantle convection. Some schemes involve force balances on individual plates. Other models drive mantle convection entirely by imposed plate motions. The possibility that has been overlooked is that the plates define and organize themselves by mutual interactions of the whole plate system and that minimization of dissipation in the lithosphere may be the organizing rule. Fluctuations of stress in such a system cause global reorganizations without a causative mantle convective event. The idea of minimum dissipation in global tectonics, but not of selforganization, was discussed briefly by Sleep et al [1979].

Semantics. The words rigid and strength as applied to plates may have diverted attention away from the operative physics. The word plate itself implies these characteristics. Clouds also move across the sky as coherent entities yet they, as do plates, constantly evolve and change form. If plate tectonics is a far-from-equilibrium self-organized dissipative system then computer simulations must allow numerous degrees of freedom, and must allow plates and plate boundaries to form naturally and spontaneously.

We speak of assessing plate "rigidity" using the closure of plate motion circuits [e.g. Stein and Gordon, 1984] and how well geodetic data are fit by a single Euler vector [e.g. Dixon et al., 1996; Newman et al.,1999]. In this paper's nomenclature these estimate "coherence" of motion. Intraplate seismicity and volcanism, in contrast, are manifestation of internal deformation, or "non-rigidity". Dikes can operate in cracks having widths of meters and these do not much affect geodynamic estimates of plate coherence or apparent rigidity.

The mantle undoubtedly provides energy and matter to the plate system and is an entropy sink but mantle convec- tion need not organize the plates. In order to self-organize the plate system needs to be treated as an open system with multiple degrees of freedom.

The plate paradigm may be a much more powerful theory than is evident in current treatments of rigid plate tectonics, midplate phenomena and mantle convection. If plates are deformable, breakable and ephemeral, then there are natural explanations for phenomena generally thought to lie outside the preview of plate tectonics, e. g. 'hotspots' [Anderson 2000, 2001ab].

Discussion. The difficulty in accounting for plate tectonics with computer simulations may be explained if plates are a self-organized system and they organize mantle convection rather than vice versa. The emphasis on temperature and strength, rather than stress, may contribute to the difficulty.

Far-from-equilibrium systems do strange things. They become inordinately sensitive to external or internal influences. Small changes can yield huge, startling effects up to and including reorganization of the entire system. We expect self-organization in slowly driven interactiondominated systems. The resulting patterns do not involve templates or tuning. The dynamics is dominated by mutual interactions, not by individual degrees of freedom. Periods of gradual change or calm quiescence are interrupted by periods of hectic activity. I suggest that such changes in the global geologic record are due to plate interactions and self-reorganizations, rather than events triggered by mantle convection. Apparent changes in orientation and activity of volcanic chains are likely to be due to changes and reorientations of stress [Favela and Anderson, 2000; Hieronymus and Bercovici, 1999; Hieronymus and Bercovici, 2000; Jackson and Shaw, 1975; McNutt et al., 1997; Turcotte and Oxburgh, 1976]. The stress-crack hypothesis seems to apply to most volcanic chains [Favela and Anderson, 2000; Jackson and Shaw, 1975; McNutt et al., 1997] [8].

Massive mantle overturns, and mantle avalanches have been proposed to explain certain aspects of plate tectonics and global magmatism [Larson, 1991; Stein and Hofmann, 1994; Tackley et al., 1993; Davies, 1999]. However, the proximity of the mantle to the melting point [Anderson, $1989 ; 2000]$ and the recognition of stress controlled magmatism [Anderson, 1998; Favela and Anderson, 2000; Jackson and Shaw, 1975; McNutt et al., 1997] obviate the need for a thermal trigger. Mantle geodynamics may be controlled from the top [Gurnis et al., 2000; Lowman and Jarvis, 1993, 1999; Anderson, 2000; Hager and O'Connell, 1981] as is Bénard convection. 
Deep mantle convection may be unrelated to plate tectonics but it can still affect the elevation of the surface and stress in the lithosphere, even if there is no material transfer [Anderson, 2001a]. These stresses are added to the plate tectonic stresses and plate induced convection. The deep mantle, even if isolated, communicates to the upper part of the Earth via Newton's and Fourier's laws. The migration and ponding of melts in the shallow mantle also affect uplift and membrane stress of the lithosphere. This can occur in the absence of plumes from the core-mantle boundary. The spilling of such melts when the uplift or stretching is such that the least compressive axis becomes horizontal ( the hydrofracture and diking condition ) may explain the rapidity of emplacement of continental flood basalts. In the plume theory the duration of these events depends on the viscosity of the lower mantle and there is no satisfactory explanation of duration or uplift history of large igneous events.

Plate tectonics is often described as "just the surface boundary layer of mantle convection." However, if most of the buoyancy and dissipation is in the plate-slab system rather than in the mantle, then mantle convection patterns should be regarded as the result, not the cause, of plate tectonics. Many phenomena that have been attributed to deep mantle processes such as large igneous provinces, rapid seafloor spreading and triple junctions may actually be the result of ridge migration, plate annexation, plate induced (passive) convection and shallow dynamic (EDGE) convection [Hardebeck and Anderson, 1996; Richter, 1973; Anderson, 1998b; Anderson, 2001a; Heller et $a l, 1996$ ] and to stress controlled magmatism. The idea that plate tectonics may be a far-from-equilibrium selforganized dissipative system is a new and undeveloped one. It clearly needs to be quantified, extended and tested.

\section{APPENDIX}

[1] Presently there are about 12 plates [Anderson, $2001 \mathrm{~b}]$. The smaller plates are arranged in a polar band that also includes the major geoid lows. The major plates (Pacific, African) are antipodal and lie over major equatorial geoid highs. There is a wide range in plate sizes and velocities. Some are growing and some are shrinking. The migrations of trenches and ridges, and the growth and shrinkage of plates may be as important in understanding plate tectonics as are driving and resisting forces. A large majority of the tectonic plates are bounded by five other plates and, in addition, have five next-nearest neighbors. This is the symmetry of the pentagonal dodecahedron, a Platonic solid. Furthermore, any plate can be reached from any other plate by crossing one or two plates in between.
Clearly, plates are a strongly interacting system and cannot be treated plate-by-plate. The plates organize each other and they probably do so in a manner as to minimize dissipation in the plate system [Sleep et al, 1979].

[2] The idea that a deep thermal boundary layer may be responsible for narrow structures such as volcanic chains is based on bottom heating of systems where effects of pressure on thermal properties are ignored (the Boussinesq approximation). In the Earth, the effects of temperature and pressure on the convection parameters cannot be ignored and these must be determined as part of the solution in a self-consistent way. Such calculations [Tackley, 1998a; Anderson, 2001a] suggest that it is highly probable that the mantle below $2000 \mathrm{~km}$ depth, and possibly below $1000 \mathrm{~km}$ depth is isolated from the surface, except by Newton's and Fourier's laws. Furthermore, it is cooling of the mantle that controls the rate of heat loss from the core. The core does not play an active role in mantle convection. The magnitude of the bottom TBL depends on the cooling rate of the mantle, the P- and T-dependence of the physical properties and the radioactivity of the deep mantle. The local Rayleigh number of the deep mantle is very low [Tackley, 1998a].

[3] Upwellings which result from instablilities of deep thermal boundary layers (TBL) are called active. Plumes, for example, are called active upwellings since they are driven by their own internal buoyancy. Most plume theories, however, utilize only the high-temperatures of these upwellings and are not complete dynamic theories. Upwellings which result from plate divergences are called passive. Midocean ridges, for example, are treated as passive. The mantle in passively spreading regions is not particularly hot, although deep isotherms are advected upwards. Convection induced by lateral temperature gradients (Edge Driven Gyres and Eddies, EDGE) is termed dynamic [Anderson, 1998b]. There are also various scales of smallscale convection associated with plate tectonics [Richter, 1973; Anderson, 1998a]. These are called sprouts and longitudinal and transverse Richter rolls.

[4] Changes in the activity and orientation of volcanic chains, such as the Emperor-Hawaiian bend, are often taken to represent changes in plate motions. These changes are extremely rapid. Forces on plates represent the integral of all driving and resisting forces and therefore change slowly. A new short slab may add a significant driving force if the mantle gets more viscous with depth. However, local stresses inside of a plate can change rapidly. I attribute the changes in volumes and orientations of volcanic chains to changes in the local stress field, not aburpt changes in plate motion. Local tension is probably required for volcanism. A ridge is weak after little or no extension. 
The magnitude of the extension is probably not important since magmafracture and dikes can actually break the lithosphere, as long as the axis of least compression is horizontal. Dikes are actually an alternative to normal faults, grabens and other geological indicators of extension. Plumes are sometimes invoked because there is often little obvious geological evidence for extension (ignoring the dikes).

[5] In the case of the Earth the surface layer has chemical buoyancy and local strength so other factors, such as lithospheric discontinuities, stress concentration or extension are required to initiate subduction.

[6] The deep mantle ( $>1000 \mathrm{~km}$ depth) has different spatial and spectral characteristics than the upper mantle and may be isolated from it in the sense that there is no exchange of material. However, density variations of the deep mantle certainly affect the surface elevation, lithospheric stress and the geoid even if the mantle is chemically stratified. Heat will also flow upwards and may influence the long wavelength thermal structure although plate tectonics and subduction may overwhelm this signature because of their shorter timescale [Anderson, 2001a]. Because of the pressure dependence of $\alpha, 1 \%$ changes in intrinsic density can irreversibly stratify the mantle [Tackley, 1998a].

[7] At equilibrium, the structure that minimizes the free energy is selected. The existence of an equivalent principle for dynamic non-equilibrium systems is an important unsolved problem. The organizing principle for plate tectonics is unknown. Since rocks are weak under tension the conditions for the existence of a plate probably involve the existence of lateral compressive forces. Plates have been described as rigid but this implies long term and long range strength. They are better described as coherent entities, organized by stress fields as well as by rheology. The corollary is that volcanic chains and plate boundaries are regions of extension. Plates probably also organize themselves to minimize dissipation.

[8] Island arcs have a large proportion of strike-slip (dissipative) resistance and these usually involve larger crustal and plate thickness than midocean transform faults. Many thrust events have a strike-slip component.

[9] Plato introduced the cyclical theory of the world in his Republic. The world was created and then left to organize itself by a set of rules. The world oscillated between order, disorder and chaos. It alternated between control by "the finger of God" and self-organization. The deity would intervene as appropriate. In Timaeus Plato distinguishes between that which always is and never becomes (being, equilibrium) and that which is always becoming but never is. Plato believed that we need both being and becoming; statis and change. The plume hypothesis has been enor- mously popular partly because it is simple, seductive and has a catchy name. Alternative theories such as propagating cracks, stress induced volcanism and extensional tectonics do not have memorable names. Plutonics can be described as the hypothesis that attributes surface processes to deep causes; plumes, super plumes, massive mantle overturns and mantle convection is considered to play the dominate and active role. The hypothesis that plates are a far-fromequilibrium self-driven self-organized system can be called platonics. In this hypothesis the upper mantle provides heat and material but is otherwise passive. The surface is constantly reorganizing itself, its boundaries and orientations of volcanic chains. There is no "finger of God" or outside template.

Acknowledgements. Warren Hamilton and Gillian Foulger have been helpful throughout the preparation of this manuscript. The comments of Seth Stein and Norm Sleep have also been very useful and have greatly improved a difficult manuscript.They were able to understand the ideas and helped me to communicate them better. This work has been supported by NSF grant EAR 9726252. This paper represents Contribution Number 8842, Division of Geological and Planetary Sciences, California Institute of Technology.

\section{REFERENCES}

Acton, G. D., S. Stein, J. F. Engeln, Block rotations and continental extension in Afar: a comparison to oceanic microplate systems, Tectonics, 10, p. 501, 1991.

Anderson, D. L., Hotspots, Polar Wander, Mesozoic Convection and the Geoid Nature 297, p. 391-393, 1982.

Anderson, D. L., Y-S. Zhang, T. Tanimoto, Plume heads, continental lithosphere, flood basalts and tomography, in Magmatism and the causes of continental break-up: Geological Society Special Publications, , vol. 68, pp. 99-124, 1992.

Anderson, D. L., The scales of mantle convection, Tectonophysics 284, p. 1-17, 1998a.

Anderson, D. L., The EDGEs of the Mantle in The Core-Mantle boundary region, AGU Geophys. Monogr. Ser., edited by M. Gurnis, M. E. Wysession, E. Knittle, B. A. Buffett, pp.255271, Washington, D. C., 1998b.

Anderson, D. L., The thermal state of the upper mantle; no role for mantle plumes, Geophys. Res. Lett. 27, 3623 (2000).Anderson, D. L., Top-Down Tectonics?, Science, 293, p. 2016-2018, (2001a).

Anderson, D. L., How Many Plates?, in press, Geology, $2001 \mathrm{~b}$.

Anderson-Fontana, S., J. F. Engeln, P. Lundgren, R. L. Larson, S. Stein, Tectonics and evolution of the Juan Fernandez microplate at the Pacific-Nazca-Antarctic triple junction, J. Geophys. Res., 91, p. 2005, 1986.

Bejan, A., Entropy generation minimization: The new thermodynamics of finite-size devices and finite-time processes, J. Appl. Phys., 79, p. 1191, 1996. 
Benard, H., Cellular vortices in a liquid layer, Rev. Gen. Sci. Pure Appl. 11, p. 1261, 1900.

Bercovici, D., Generation of plate tectonics from lithospheremantle flow and void-volatile self-lubrication, Earth Planet. Sci. Lett. 154, p. 139-151, 1998.

Cates, M. E., J. P. Wittmer, J. P. Bouchaud, Claudin, P., Jamming Force Chains and Fragile matter, Phys. Rev. Lett. 81, p. 1841$1844,1998$.

Christensen, U., Thermal evolution models for the Earth, J. Geophys. Res. 90, p. 2995-3007, 1985.

Conrad, C. P., B. H. Hager, The thermal evolution of an Earth with strong subduction zones, Geophys. Res. Lett. 26, p. 3041 3044, 1999.

Davies, G. F., Plates, Plumes, and Mantle Convection, Dynamic Earth, Cambridge University, Cambridge, pp.458, 1999.

Dixon, T. H., A. Mao, S. Stein, How rigid is the stable interior of the North American plate?, Geophys. Res. Lett. 23, p. 3035 , 1996.

Dziewonski, A., Global seismic tomography: past, present and future in Problems in Geophysics for the New Millennium, edited by E. Boschi, G. Ekstrom, A. Morelli, Editrice Compositori, pp. 289-349, Rome, 2000

Engeln, J. F., S. Stein, Tectonics of the Easter plate, Earth Planet. Sci. Lett., 68, p. 259, 1984.

Engeln, J. F., S. Stein, J. Werner, R. Gordon, Microplate and shear zone models for oceanic spreading center reorganizations, J. Geophys. Res. 93, p. 2839, 1988.

Favela, J., D. L. Anderson, Extensional tectonics and global volcanism in Problems in Geophysics for the New Millennium, edited by E. Boschi, G. Ekstrom, A. Morelli, Editrice Compositori, pp. 463-498, Rome, 2000.

Forsyth, D. W., S. Uyeda, On the relative importance of the driving forces of plate motion, Geophys. J. Roy. Astr. Soc. 43, p. 163-200, 1975.

Gordon, R. G., Diffuse Oceanic Plate Boundaries in The History and Dynamics of Global Plate Motions, Geophys. Monogr. Ser., edited by M. Richards, R. Gordon, R. van der Hilst, pp. 398, Washington D. C., 2000.

Gurnis, M., Large-Scale Mantle Convection and the Aggregation and Dispersal of Supercontinents, Nature 332, p. 695, 1988.

Gurnis, M., S. Zhong, Generation of Long Wavelength Heterogeneity in the Mantle By the Dynamic Interaction Between Plates and Convection, Geophys. Res. Lett. 18, p. 581-584, 1991.

Gurnis, M., S. Zhong, J. Toth, On the Competing Roles of Fault Reactivation and Brittle Failure in Generating Plate Tectonics from Mántle Convection, in The history and dynamics of global plate motions, Geophys. Monogr., pp.73., Washington D. C., 2000

Hager, B. H., R. J. O'Connell, A simple global model of plate dynamics and mantle convection, J. Geophys. Res., 86, p. 4843-4878, 1981 ..

Hardebeck, J., D. L. Anderson, Eustasy as a test of a Cretaceous Superplume Hypothesis, Earth Planet. Sci. Lett. 137, p. 101$108,1996$.
Heller, P. L., D. L. Anderson, C. L. Angevine, Is the Middle Cretaceous Pulse of Rapid Seafloor Spreading Real or Necessary?, Geology, 24, p. 491-494, 1996.

Hieronymus, C. F., D. Bercovici, Discrete alternating hotspot islands formed by interaction of magma transport and lithospheric flexure, Nature 397, p. 604-607, 1999.

Hieronymus, C. F., D. Bercovici, Non-hotspot formation of volcanic chains: control of tectonic and flexural stresses on magma transport, Earth Planet. Sci. Lett. 181, p. 539-554, 2000.

Jackson, S., H. R. Shaw, Stress Field in Central Portions of the Pacific Plate: Delineated in Time by Linear Volcanic Chains, $J$. Geophys. Res. 80, p. 1861, 1975.

King, S. D., J. Ritsema, African hotspot volcanism: small-scale convection in the upper mantle beneath cratons, Science 290 , p. 1137-1140, 2000.

King, S. D., D. L. Anderson, Edge-driven convection, Earth Planet. Sci. Lett. 160, p. 289-296, 1998.

Korenaga, J., Magmatism and dynamics of continental breakup in the presence of a mantle plume, Ph. D. Thesis, M.I.T., Cambridge, 2000.

Larson, R. L., Latest Pulse of Earth - Evidence For a Midcretaceous Superplume Geology 19, p. 547-550, 1991.

Lowman, J. P., G. T. Jarvis, Mantle Convection Flow Reversals Due to Continental Collisions, Geophys. Res. Lett. 20, p. $2087-$ 2090, 1993.

Lowman, J. P., G. T. Jarvis, Effects of mantle heat source distribution on supercontinent stability, J. Geophys. Res. 104, p. 12733-12746, 1999.

McCaffrey, R., Slip partitioning at convergent plate boundaries of SE Asia, Tectonic Evolution of Southeast Asia, Geol. Soc. Spec. Publ., edited by R. Hall, D. Blundell, vol. 106, pp.3-18, London, 1996.

McNutt, M. K., D. W. Caress, J. Reynolds, K. A. Jordahl, R. A. Duncan, Failure of plume theory to explain midplate volcanism in the southern Austral islands, Nature 389, p. 479-482, 1997.

Miller, S. A., A. Nur, Permeability as a toggle switch in fluidcontrolled crustal processes, Earth Planet. Sci. Lett. 183, p. 133-146, 2000.

Monnereau, M., S. Quere, Spherical shell models of mantle convection with tectonic plates, Earth Planet. Sci. Lett. 184, 575 587, 2001.

Naar, D. F., R. N. Hey, Recent Pacific-Easter-Nazca plate motions in Evolution of Mid Ocean Ridges, IUGG Symposium 8, Geophys. Monogr. Ser., pp. 9, 1989 b.

Newman, A., S. Stein, J. Weber, J. Engeln, A. Mao, T. Dixon, Slow deformation and lower seismic hazard at the New Madrid Seismic Zone, Science 284, p. 619, 1999.

Norabuena, E., T. Dixon, S. Stein, C. Harrison, Decelerating Nazca-South America convergence and Nazca-Pacific spreading, Geophys. Res. Lett. 26, p. 3405, 1999

O'Connell, R. J., C. W. Gable, B. H. Hager, Toroidal-polidal partitioning of lithospheric plate motions in Glacial isostasy, sea-level and mantle rheology, edited by R. Sabodini, K. Lam- 
beck, E. Boschi, vol. 334, pp. 535-551, Dordrecht-Boston, Rome, 1990.

Ottino, J. M., D. V. Khakhar, Mixing and segregation of granular materials, Annu. Rev. Fluid. Mech. 32, p. 55, 2000.

Pearson, J. R. A., On convection cells induced by surface tension, J. Fluid Mech. 4, pp.489-500, 1958.

Prigogine, I., Time and Complexity In The Physical Sciences, in From Being to Becoming, edited by W.H. Freeman, pp. 257262, San Francisco, 1980.

Rayleigh, L., On Convection Currents in a Horizontal Layer of Fluid, when the Higher Temperature is on the Under Side, Philos. Mag. 32, p. 529-546, 1916.

Richter, F. M., Convection and the large-scale circulation of the mantle, J. Geophys. Res. 78, p. 8735-8745, 1973.

Ritsema, J., H. j. van Heijst, Seismic Imaging of structural heterogeneity in Earth's mantle: evidence for large-scale mantle flow, Sci. Prog. 83, p. 243, 2000.

Rona, P., E. Richardson, Early Cenozoic global plate reorganization, Earth Planet. Sci. Lett. 40, p. 1-11, 1978.

Rubin, A., Propagation of Magma-filled cracks, Ann. Rev. Earth Planet. Sci. 43, p. 287-336, 1995.

Schlanger, S. O., M. O. Garcia, B. H. Keating, J. J. Naughton, W. W. Sager, J. A. Haggerty, J. A. Philpotts, R. A. Duncan, Geology and geochronology of the Line Islands, J. Geophys. Res. 89, p. 11,261, 1984.

Scriven, L. E., C.V. Sternling, The Marangoni Effects, Nature, 187, p. 186-188, 1960.

Sleep, N. H., S. Stein, R. J. Geller, R. G. Gordon, The use of the minimum-dissipation principle in tectonophysics, Earth Planet. Sci. Lett 45, p. 218-220, 1979.

Sleep, N. H., Evolution of the mode of convection within terrestrial planets, J. Geophys. Res. 105, p. 17563-17578, 2000.

Solomatov, V. S., L. N. Moresi, Three regimes of mantle convection with non-Newtonian viscosity and stagnant lid convection on the terrestrial planets, Geophys. Res. Lett. 24, p. 1907-1910, 1997.

Stein, S., H. J. Melosh, J. B. Minster, Ridge migration and asymmetric sea-floor spreading, Earth Planet. Sci. Lett. 36, p. $51,1977$.

Stein, S., R. G. Gordon, Statistical tests of additionsal plate bnoundaries from plate motion inversions, Earth Planet. Sci. Lett. 69, p. 401, 1984

Stein, M., A. W. Hofmann, Mantle Plumes and Episodic Crustal Growth, Nature 372, p. 63-68, 1994.
Stein, S., G. F. Sella, E. A. Okal, The January 26, 2001 Bhuj earthquake and the diffuse western boundary on the Indian plate, (?).

Tackley, P. J., D. J. Stevenson, G. A. Glatzmaier, G. Schubert, Effects of an Endothermic Phase-Transition At $670 \mathrm{Km}$ Depth in a Spherical Model of Convection in the Earths Mantle, $\mathrm{Na}$ ture, 361, p. 699-704, 1993.

Tackley, P. J., Self-consistent generation of tectonic plates in three- dimensional mantle convection, Earth Planet Sci. Lett. 157, p. 9-22, 1998 b.

Tackley, P. J., Three-dimensional simulations of mantle convection with a thermo-chemical basal boundary layer: D"? in The Core-mantle boundary region, edited by $\mathrm{M}$. Gurnis, M. E. Wysession, E. Knittle, B. A. Buffett, Geophys. Monogr. Ser., pp. 231-253, Washington, D. C., 1998a.

Tanimoto, T., Predominance of Large-Scale Heterogeneity and the shift of velocity anomalies between the upper and lower mantle, J. Phys. of the Earth, 38, p. 493, 1990.

Trappe, V., V. Prasad, L. Cipelletti, P. N. Segre, D. A. Weitz, Jamming phase diagram for attractive particles, Nature 411 , p. 772-775, 2001.

Turcotte, D. L., E. R. Oxburgh, Stress accumulation in the lithosphere, Tectonophysics 35, p. 183-199, 1976.

Turcotte, D. L., G. Schubert, Applications of continuum physics to geological problems in Geodynamics, New York, pp. 450, 1982.

van Keken, P. E., C. J. Ballentine, Whole-mantle versus layered mantle convection and the role of a high-viscosity lower mantle in terrestrial volatile evolution, Earth Planet. Sci. Lett. 156, p. 19-32, 1998.

Velarde, M. G., C. Normand, Convection, Sci. Am. 243, p. 92108, 1980.

Weaire, D., S. Hutzler, The Physics of Foam, pp. 246, Clarendon Press, Oxford, 1999.

Zhong, S., M. Gurnis, Towards a realistic simulation of plate margins in mantle convection, Geophys. Res. Lett. 22, p. 981, 1995.

Don L. Anderson, Department of Geology and Planetary Sciences, California Institute of Technology, Pasadena, California 